\title{
Circulatory effects of fast ventilator rates in preterm infants
}

\author{
A C Fenton, D J Field, K L Woods, D H Evans, M I Levene
}

\begin{abstract}
High frequency positive pressure ventilation has been suggested to result in a lower incidence of respiratory complications in preterm infants with idiopathic respiratory distress syndrome compared with ventilation at conventional rates. A possible disadvantage is compromise of the infant's cardiovascular condition secondary to inadvertent positive end expiratory pressure (PEEP). In a group of 20 such infants treated with high frequency positive pressure ventilation (rates of up to $100 /$ minute) and paralysed, changes in arterial blood pressure and cerebral blood flow velocity were largely influenced by changes in arterial blood gases, and no effect could be attributed to inadvertent PEEP. In addition, the observed fall in both arterial carbon dioxide and oxygen tensions could be readily predicted for theoretical reasons. Under certain conditions at the fastest rates used, cerebral blood flow velocity was significantly influenced by changes in blood pressure, which may indicate impaired cerebrovascular regulation. Though other factors (such as the severity of the infants' illness or the use of paralysis) may have been responsible for this apparent blood pressure passivity, the role of high frequency positive pressure ventilation in such infants warrants further study.
\end{abstract}

During recent years the type of infant treated in neonatal units has changed, ${ }^{1}$ and the extremely immature infants now encountered regularly are at great risk from the respiratory complications of idiopathic respiratory distress syndrome. In addition, neonatal ventilators are now more sophisticated and these factors have led to different patterns of ventilation being tried in attempts to minimise the complications of respiratory support.

The use of one such alternative, high frequency positive pressure ventilation, has been increasing in neonates, because of a reported reduction of harmful interaction with the infant's own respiratory efforts, ${ }^{2}$ as well as an improvement in oxygenation in unparalysed infants. ${ }^{3}$ Concerns about high frequency positive pressure ventilation have centred around the production of inadvertant positive end expiratory pressure (PEEP), ${ }^{4}$ resulting from insufficient time for the lungs to empty during the expiratory phase. This may lead to harmful secondary effects on both the lungs and the cardiovascular system. The former effect may impair blood gases and the latter may produce a number of secondary problems, for example decreased venous return, ${ }^{5}$ or restriction of left ventricular filling. ${ }^{6}$

Several factors are likely to influence the occurrence of inadvertant PEEP and whether its effects are transmitted to the cardiovascular system. Theoretically, it is more likely to occur in paralysed infants who cannot expire actively, and also if the degree of air leak around the endotracheal tube is relatively small. Mechanical transmission of inadvertant PEEP to the cardiovascular system will be affected by lung compliance, ${ }^{7}$ which will vary with the stage of idiopathic respiratory distress syndrome. To assess the magnitude of these potential cardiovascular effects we have studied the changes produced by high frequency positive pressure ventilation on arterial blood pressure and cerebral blood flow velocity in a group of paralysed infants in the acute phase of idiopathic respiratory distress syndrome to see whether any of the changes that occurred could be attributed to inadvertent PEEP.

\section{Patients and methods}

The study was carried out on the neonatal unit at the Leicester Royal Infirmary between June 1988 and August 1989. Twenty infants were studied on one occasion each. Their birth weights ranged from 720-2420 g (median 1480 g) and their gestational ages from 25-34 weeks (median 30 weeks). The median age at the time of study was 54.5 hours. Median peak inspiratory pressure at the time of the study was $24 \mathrm{~cm}$ $\mathrm{H}_{2} \mathrm{O}$ and median inspired oxygen concentration was 0.73 . Full details of the infants are given in the table.

Infants were considered eligible for the study if they were being ventilated for respiratory distress syndrome and were paralysed with pancuronium to facilitate ventilation. The decision to use pancuronium was based on the inability to ventilate the infant satisfactorily at either slow or fast rates and was made independently by the clinicians responsible for the infants' care. All infants had indwelling arterial catheters (either umbilical or radial) for clinical reasons and were intubated orally with shouldered endotracheal tubes. An infant was excluded if a pneuomothorax was present, if there was pre-existing intraventricular haemorrhage, or if the infant's condition was unstable.

The study was approved by the Leicestershire district ethics committee. Informed parental consent was obtained before all studies and parents were encouraged to be present for the duration of the study. The following variables were recorded:
Correspondence to: Dr Field.

Accepted 26 March 1990 
Details of infants at time of study

\begin{tabular}{|c|c|c|c|c|c|c|}
\hline Case No & $\begin{array}{l}\text { Gestation } \\
\text { (weeks) }\end{array}$ & $\begin{array}{l}\text { Birth weight } \\
(\mathrm{g})\end{array}$ & $\begin{array}{l}\text { Age at } \\
\text { study (hours) }\end{array}$ & $\begin{array}{l}\text { Fractional } \\
\text { inspiratory oxygen }\end{array}$ & $\begin{array}{l}\text { Peak inspiratory } \\
\text { pressure }\left(\mathrm{cm} \mathrm{H}_{2} \mathrm{O}\right)\end{array}$ & $\begin{array}{l}\text { Positive end } \\
\text { expiratory pressure } \\
\left(\mathrm{cm} \mathrm{H}_{2} \mathrm{O}\right)\end{array}$ \\
\hline $\begin{array}{r}1 \\
2 \\
3 \\
4 \\
5 \\
6 \\
7 \\
8 \\
9 \\
10 \\
11 \\
12 \\
13 \\
14 \\
15 \\
16 \\
17 \\
18 \\
19 \\
20\end{array}$ & $\begin{array}{l}29 \\
30 \\
32 \\
32 \\
31 \\
30 \\
30 \\
29 \\
32 \\
26 \\
32 \\
30 \\
27 \\
29 \\
25 \\
31 \\
27 \\
30 \\
31 \\
34\end{array}$ & $\begin{array}{r}900 \\
1500 \\
2000 \\
2070 \\
1990 \\
1700 \\
1280 \\
1360 \\
2070 \\
880 \\
1790 \\
1550 \\
1100 \\
1400 \\
750 \\
1450 \\
1060 \\
720 \\
1600 \\
2420\end{array}$ & $\begin{array}{r}124 \\
77 \\
66 \\
66 \\
73 \\
14 \\
81 \\
43 \\
20 \\
57 \\
21 \\
49 \\
216 \\
22 \\
16 \\
38 \\
144 \\
86 \\
23 \\
52\end{array}$ & $\begin{array}{l}0.86 \\
0.75 \\
0.60 \\
0.80 \\
0.70 \\
1.00 \\
0.98 \\
0.78 \\
0.58 \\
0.96 \\
0.84 \\
0.70 \\
0.35 \\
0.58 \\
1.00 \\
0.58 \\
0.65 \\
0.50 \\
0.46 \\
1.00\end{array}$ & $\begin{array}{l}22 \\
28 \\
20 \\
23 \\
26 \\
32 \\
31 \\
25 \\
20 \\
26 \\
35 \\
25 \\
15 \\
20 \\
20 \\
20 \\
20 \\
20 \\
28 \\
32\end{array}$ & $\begin{array}{l}2 \\
2 \\
2 \\
3 \\
4 \\
4 \\
3 \\
2 \\
2 \\
2 \\
4 \\
2 \\
2 \\
3 \\
2 \\
4 \\
3 \\
3 \\
2 \\
3\end{array}$ \\
\hline
\end{tabular}

Cases 6, 10, and 15 died of idiopathic respiratory distress syndrome.

CEREBRAL BLOOD FLOW VELOCITY AND ARTERIAL BLOOD PRESSURE

In three of the infants cerebral blood flow velocity recordings were made from the anterior cerebral artery using an ATL 600 duplex Doppler system with a $724 \mathrm{~A}$ probe (pulse echo 7.5 $\mathrm{MHz}$, Doppler frequency $5 \mathrm{MHz}$ ). One anterior cerebral artery was visualised in the sagittal plane through the anterior fontanelle and signals were recorded from a point midway between the most inferior border of the corpus callosum and the vessel's origin in the circle of Willis. Care was taken to ensure that the angle of insonation of the vessel was less than $10^{\circ}$.

For these recordings the Doppler sample value was set to $3 \mathrm{~mm}$ and the high pass wall filter at its lowest value $(100 \mathrm{~Hz})$. Doppler signals were recorded on to digital audiotape and subsequently replayed through a fast Fourier transform analyser. ${ }^{8}$ The maximum frequency envelope of 20 or more consecutive beats was extracted and calibrated in terms of velocity using the Doppler equation. The mean velocity over the cardiac cycle was estimated by halving the mean value of the maximum velocity over the cycle. ${ }^{9}$ In these infants, a permanent record of blood pressure was made on a chart recorder.

The remaining 17 infants studied had cerebral blood flow velocity measurements recorded from one middle cerebral artery using a miniature probe attached to the infant's skin, which we have previously described. ${ }^{10} 11$ This system also collects data about blood pressure from the indwelling arterial line and displays the information graphically at the cotside. This obviates the need to handle the infant repeatedly to make estimations of cerebral blood flow velocity. Results may also be retrieved off line at a later stage. In all infants, mean arterial blood pressure was recorded at each stage of the study.

\section{RESPIRATORY RECORDINGS}

Ventilator pressures were recorded from the endotracheal tube through a 19 gauge needle connected to a pressure transducer. Tidal volumes were recorded using a Gaeltec pneumo- tachograph (with a bias flow system to eliminate dead space) combined with a differential pressure transducer and integrator as described previously. ${ }^{12}$ All signals were recorded on a chart recorder for later analysis.

\section{STUDY PROCEDURE}

After the recording apparatus had been attached, a period of 15 minutes was allowed for stabilisation of the infant's condition. All infants were then studied at three ventilatory rates: $30-40,50-60$, and $100 /$ minute, using a Sechrist ventilator (model IV-100B). Peak inspiratory pressure, PEEP, and inspiratory: expiratory ratio were kept constant. The rate change sequence was initially an increase in all cases, as all infants entered the study while being ventilated at either $30-40$ or $50-60$ / minute. Infants entering at $30-40 /$ minute had their rate increased by at least 20 /minute as a first step. Those entering at 50-60/minute were increased to $100 /$ minute and then reduced to $30 /$ minute as a last stage before returning to their baseline rate.

At 100/minute, a second set of recordings were made with the pneumotachograph bias flow switched off. This manoeuvre was performed to enable comparison of the cardiovascular effects of the rate change at different arterial carbon dioxide pressure $\left(\mathrm{PaCO}_{2}\right)$. A 12 minute stabilisation period was allowed after each rate change before measurements were made of mean arterial blood pressure, cerebral blood flow velocity, tidal volume, peak inspiratory pressure, and PEEP. Even at the fastest rates, the ventilator pressure wave flattened out. At each stage $0.1 \mathrm{ml}$ of blood was taken through the arterial line for measurement of $\mathrm{PaCO}_{2}$ and arterial oxygen pressure $\left(\mathrm{PaO}_{2}\right)$.

\section{STATISTICAL ANALYSIS}

Parametric statistical tests were used. Paired $\boldsymbol{t}$ tests were used to compare observed values of $\mathrm{PaO}_{2}, \mathrm{PaCO}_{2}$, mean arterial blood pressure, and cerebral blood flow velocity at the four ventilator settings. No adjustment was made for 
multiple comparisons. The principal findings would not have been altered by this adjustment, which was judged unnecessary because of the small number of comparisons being made. Linear regression analysis was used to examine the factors influencing changes in cerebral blood flow velocity. A step down analysis was used, incorporating $\mathrm{PaCO}_{2}, \mathrm{PaO}_{2}$, and mean arterial blood pressure as potential explanatory variables. The adequacy of the linear model was checked by plotting residuals.

Results

$\mathrm{PaO}_{2}$ changed little at the different ventilator settings, but was significantly lower at $100 /$ minute than at $30 /$ minute $(p=0.043)$ (fig 1$)$. $\mathrm{PaCO}_{2}$ was signifjeantly lower at 60 /minute $(\mathrm{p}=$ $0.0003)$, and at $100 /$ minute $(p=0.016)$, than at $30 /$ minute (fig 2). With the bias flow turned off at 100 /minute, however, $\mathrm{PaCO}_{2}$ was not significantly different from that observed at 30 /minute $(p=0.7)$. There was a substantially higher $\mathrm{PaCO}_{2}$ at 100 /minute with the bias flow turned off than at the same rate with the pump on $(p=0 \cdot 004)$.

There was a slight downward trend in mean arterial blood pressure at increasing ventilation

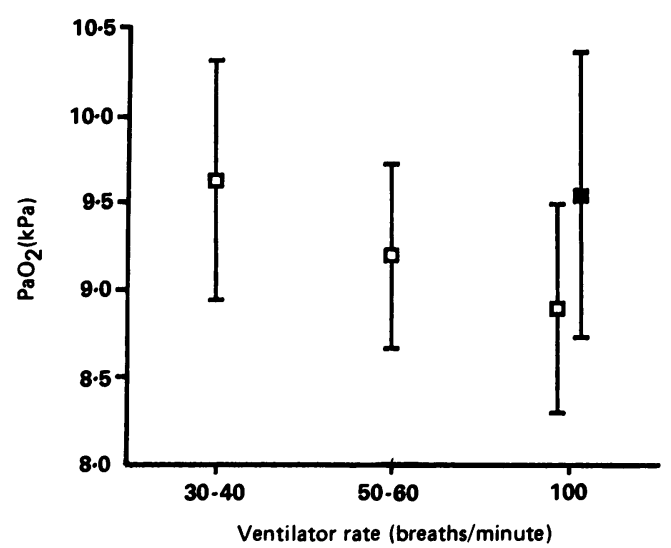

Figure $1 \mathrm{Mean}(\mathrm{SEM}) \mathrm{PaO}_{2}$ at different ventilator rates. Open symbols represent bias flow on, shaded symbol represents bias flow off.

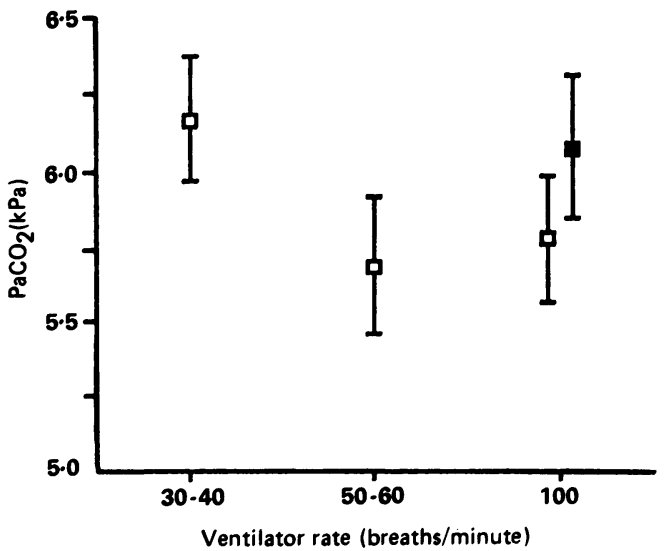

Figure $2 \mathrm{Mean}(\mathrm{SEM}) \mathrm{PaCO}_{2}$ at different ventilator rates. Open symbols represent bias flow on, shaded symbol represents biasflow off. Increasing minute ventilation resulted in an initial fall in $\mathrm{PaCO}$, until tidal ventilation resulted in an initial fall in $\mathrm{PaCO}$, until tidal

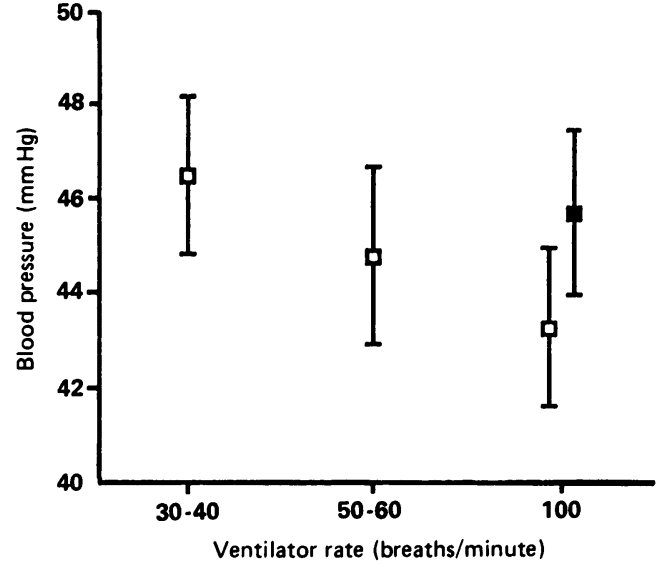

Figure 3 Mean(SEM)blood pressure at different ventilator rates. Open symbols represent biasflowon, shaded symbol represents biasflowoff.

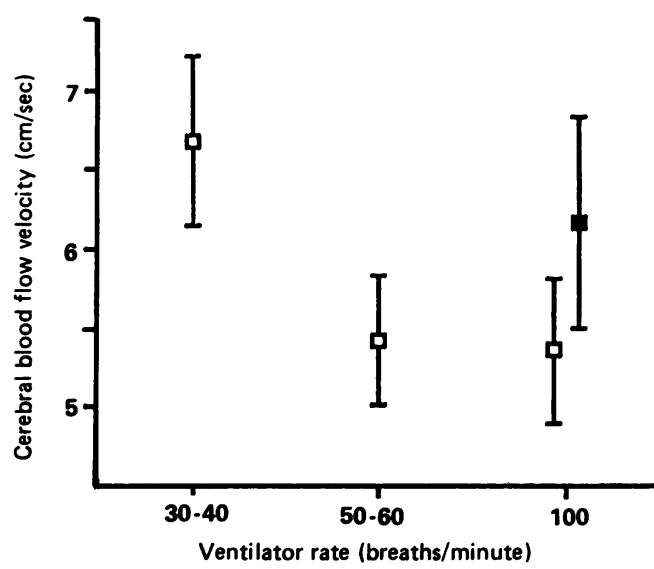

Figure4 Mean(SEM)cerebralblood flowvelocityat different ventilator rates. Open symbols represent biasflow on, shaded symbol represents biasflow off.

rates, which was significant at $100 /$ minute compared with $30 /$ minute $(p=0.043)$. Turning the bias flow off at 100 /minute, however, resulted in a clear increase in mean arterial blood pressure $(p=0.003)$ compared with the same rate with the pump on (fig 3 ). The statistical analysis suggested that this did not depend significantly on the accompanying changes in blood gases.

Cerebral blood flow velocity fell as ventilator rate was increased from 30 to 60 /minute $(p=0.0017)$, but showed no further fall on further increasing the rate to $100 /$ minute $(p=0.74)$. Removal of the bias flow at this rate resulted in a clear rise in cerebral blood flow velocity $(p=0.008)$ to the level observed at 30 breaths/minute (fig 4). Stepwise linear regression indicated that two separate factors were associated with the observed changes in cerebral blood flow velocity. Firstly, as ventilator rate was changed from 30 to 100 /minute, the change in cerebral blood flow velocity was closely associated with the change in $\mathrm{PaCO}_{2}(\mathrm{p}=0.008)$, but was independent of changes in $\mathrm{PaO}_{2}$ or blood pressure. The variation in $\mathrm{PaCO}_{2}$ alone was sufficient to account for $30 \%$ of the variability in the change of cerebral blood flow velocity.

Secondly, the rise in cerebral blood flow 
velocity on removal of the bias flow at 100 / minute was not related to the change in $\mathrm{PaCO}_{2}$, but was significantly dependent on the change in mean arterial blood pressure $(p=0.014)$. Once the change in mean arterial blood pressure had been included in the regression model, the effect of the change in $\mathrm{PaCO}_{2}$ was not significant $(p=0.14)$; neither was the effect of the change in $\mathrm{PaO}_{2}(\mathrm{p}=0.9)$. Twenty nine per cent of the variability in the change in cerebral blood flow velocity resulting from the removal of the bias flow was attributable to the associated change in mean arterial blood pressure.

\section{Discussion}

There is relatively little data on the effects of inadvertent PEEP in preterm infants which occurs even at relatively slow ventilator rates. ${ }^{4}$ Our findings indicate that the use of high frequency positive pressure ventilation in paralysed infants with stable idiopathic respiratory distress syndrome does not result in adverse haemodynamic effects or changes in blood gases that might be attributable to inadvertent PEEP.

In a study such as this, standardisation of patients by stage of disease is clearly important. The criteria for the use of pancuronium were well defined and all the infants were studied when their ventilatory requirements were stable.

Important factors determining the production of inadvertent PEEP are lung compliance and the amount of air leak around the endotracheal tube. ${ }^{4} \mathrm{We}$ attempted to measure static compliance in all of our infants using a prolonged inspiration technique, but were unable to prevent significant air leaks in 18 of the infants studied, despite the use of shouldered endotracheal tubes. The two infants in whom successful measurements were made had compliances of 0.5 and $0.6 \mathrm{ml} / \mathrm{cm} \mathrm{H}_{2} \mathrm{O}$, respectively. As major leaks around the endotracheal tubes occurred in most of our infants, it seems likely that this effect limits the tendency to develop inadvertent PEEP. As our clinical practise in regard to type and size of endotracheal tube used is similar to that in many neonatal units, we believe that inadvertent PEEP does not pose a clinically important problem in paralysed infants.

A potential criticism of our method in view of the air leak is that rather than measuring tidal volumes, we were in fact merely recording changes in air leak. Though this may be true to some extent, the rise in minute volumes we recorded (fig 5) were accompanied by concurrent falls in $\mathrm{PaCO}_{2}$ between 30 and 60 breaths/ minute, which would not have occurred if the changes measured had merely represented alterations in air leak. The subsequent rises in $\mathrm{PaCO}_{2}$ between 60 and 100 breaths/minute despite further rises in minute volume probably resulted from the fall in tidal volume at the higher rate (fig 5) rendering it less effective.

The significant fall in $\mathrm{PaO}_{2}$ between slow and fast rates may also be predicted from theoretical principles, as increasing ventilator rate alone (that is, producing an increased number of ventilator up strokes/unit time) will result in

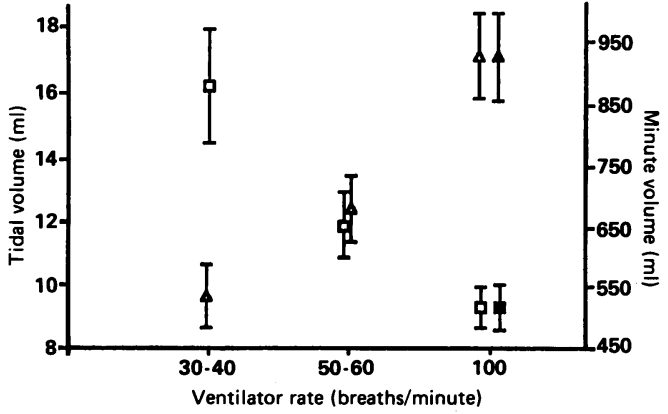

Figure 5 Mean (SEM)tidal $(\square)$ and minute $(\triangle)$ volumes with increasing ventilatorrates. Open symbols represent bias flowon, shaded symbols represent biasflow. off.

a fall in mean airway pressure, thus directly affecting oxygenation.

Our findings are in contrast to those of Greenough et al, who found that the use of high frequency positive pressure ventilation did not result -in significant changes in arterial blood gases. ${ }^{13}$ We suspect that these findings result from differences in methods. Firstly, half the infants in this study were ventilated with Bourns ventilators, which in our experience are less efficient at rates of 100/minute. Secondly, flow rates were altered to maintain mean airway pressure while keeping inspiratory:expiratory ratios and peak inspiratory pressure constant. To do this, an increase in PEEP must have been required (not stated in the paper), which would have negated the changes in $\mathrm{PaCO}_{2}$ and $\mathrm{PaO}_{2}$ that we observed.

It has been recognised in animal studies since the last century that changes in blood gases have an important influence on the cerebral vasculature, ${ }^{14}$ but the full extent of this effect on cerebral blood flow had to await reliable methods of estimating cerebral blood flow in humans. ${ }^{15}$ Models for cerebral injury in preterm neonates have hypothesised that there is impaired cerebrovascular regulation, ${ }^{16}$ with vascular 'watershed' regions notably in the periventricular white matter most at risk from ischaemia. If the normal regulatory mechanisms fail to operate, 'pressure passive' blood flow may result, but evidence for this is scanty and has been obtained from heterogeneous groups of infants. ${ }^{17}$

The finding that in particular circumstances changes in mean arterial blood pressure seemed to exert more influence on cerebral blood flow velocity (and thus actual cerebral blood flow) ${ }^{18}$ than $\mathrm{PaCO}_{2}$ was unexpected. Though care must be taken in attaching clinical importance to significant results generated unexpectedly from statistical analysis, several points are of note. Firstly, for this apparent relationship to have resulted from the statistical analysis alone is unlikely, as not only was the significance of the effect of mean arterial blood pressure gained, but that of $\mathrm{PaCO}_{2}$ lost. Secondly, an effect secondary to the order of rate changes during the study would have been expected to have an opposite effect to that seen. Thirdly, this effect was observed at carbon dioxide tensions encountered at other times in the study and it is 
therefore unlikely that maximal cerebrovascular dilatation secondary to changes in $\mathrm{PaCO}_{2}$ had been achieved. Were this the case, changes in blood pressure may indeed have had a more prominent influence on cerebral blood flow, resulting in pressure passive cerebral blood flow.

Finally, this group of infants represents some of the illest treated in our unit, and the apparent dependence of cerebral blood flow velocity on mean arterial blood pressure may actually represent impaired cerebrovascular regulation. It is, however, important to bear in mind that $\mathrm{PaCO}_{2}$ acts both by direct and indirect (that is, sympathetically mediated) mechanisms on the cardiovascular system, ${ }^{19}$ and thus may still be the governing factor in the responses observed. In addition, we may have been observing the effect of other factors-for example, those secondary to the use of paralysing agents.

The rise in $\mathrm{PaO}_{2}$ observed with the bias flow turned off was also unexpected. We suspect that this too may have resulted from an indirect effect of the change in $\mathrm{PaCO}_{2}$ mediated by changes in mean arterial blood pressure. This would in turn raise left atrial pressure and alter shunting. Interestingly, none of the surviving infants subsequently developed ultrasound evidence typical of preterm cerebral injury. ${ }^{20}$

In summary, the use of high frequency positive pressure ventilation in paralysed infants does not seem to result in adverse cardiovascular effects that are attributable to inadvertent PEEP. In addition, it results in statistically significant (though not necessarily clinically relevant) changes in arterial blood gases, which would appear to be readily predictable from theoretical considerations. Under certain conditions these infants had changes in cerebral blood flow velocity that may have been to a certain degree dependent on changes in blood pressure. The use of ventilator rates greater than 50 or 60 breaths/minute in paralysed infants seems to confer no advantage and may in fact be detrimental. Clearly their role in such infants requires further study.

ACF was supported by the Spastics' Society.
1 Field DJ, Milner AD, Hopkin IE, Madeley RJ. Changing overall workload in neonatal units. Br Med f 1985;290: $1539-42$

2 Pohlandt F, Bernsau V, Feilen KD, et al. Reduction in barotrauma in ventilated neonates by increase in ventilator frequency: first results of a prospective collaborative and randomised trail of two different ventilatory techniques. Pediatr Res 1985;19:1077.

3 Field DJ, Milner AD, Hopkin IE. Manipulation of ventilator settings to prevent active expiration against positive pressure inflation. Arch Dis Child 1985;60:1036-40.

4 Simbruner G. Inadvertent positive end-expiratory pressure in mechanically ventilated newborn infants: detection and effect on lung mechanics and gas exchange. 7 Pediatr 1986 108:589-95.

5 Morgan BC, Martin WE, Hornbein TF, Crawford EW, Guntheroth WG. Haemodynamic effects of intermittent positive pressure respiration. Anesthesiology 1966;27: positive

6 Jardin F, Farcot J-C, Boisante L, Curien N, Margairaz A, Bourdarias J-P. Influence of positive end-expiratory pourdarias J-P. Influence of positive end-expiratory pressure on left

7 Mirro R, Busija D, Green R, Leffler C. Relationship between mean airway pressure, cardiac output and organ blood flow with normal and decreased respiratory compliance. f Pediatr 1987;111:101-6.

8 Schlindwein FS, Smith MJ, Evans DH. Spectral analysis of Doppler signals and computation of the normalised first moment in real time using a digital signal processor. Med Biol Eng Comput 1988;26:228-32.

9 Evans DH, Schlindwein FS, Levene MI. The relationship between time averaged intensity weighted mean velocity and time averaged maximum velocity in neonatal cerebral arteries. Ultrasound Med Biol 1989;15:429-35.

10 Fenton AC, Evans DH, Levene MI. On line cerebral blood flow velocity and blood pressure measurement in neonates: a new method. Arch Dis Child 1990;65:11-4.

11 Evans DH, Schlindwein FS, Levene MI. An automatic system for capturing and processing ultrasonic Doppler signals and blood pressure signals. Clin Phys Physiol Meas 1989;10:241-51.

12 Shortland DB, Field D, Gibson NA, Woods KL, Evans DH, Levene MI. Cerebral haemodynamic effects of changes in positive end expiratory pressure in the preterm infant. Arch Dis Child 1989;64:465-9.

13 Greenough A, Pool J, Greenall F, Morley C, Gamsu H. Comparison of different rates of artificial ventilation in preterm infants with respiratory distress syndrome. Acto Paediatr Scand 1987;76:706-12.

14 Donders FC. Die Bewegungen des Gehirns und die Veranderungen der Gefassfullung der pia mater. Schmid's Fahrbucher 1851;69:16-20.

15 Kety SS, Schmidt CF. The effects of altered arterial tension of carbon dioxide and oxygen on cerebral blood flow and cerebral oxygen consumption of normal young men. $\mathcal{f}$ Clin Invest 1948;27:484-92.

16 Pape KE, Wigglesworth JS. Haemorrhage, ischaemia and the perinatal brain. Clinics in Developmental Medicine 69/70. perinatal brain. Clinics in Development

17 Lou HC, Lassen NA, Friis-Hansen B. Impaired autoregulation of cerebral blood flow in the distressed newborn infant. f Pediatr 1979;94:118-21.

8 Batton DG, Hellmann J, Hernandez MJ, Maisels MJ. Regional cerebral blood flow, cerebral blood velocity and pulsatility index in newborn dogs. Pediatr Res 1983;17: 908-12.

19 Cullen DJ, Eger EI. Cardiovascular effects of carbon dioxide in man. Anesthesiology 1974;40:345-9.

20 Graham M, Levene MI, Trounce JQ, Rutter N. Prediction of cerebral palsy in very low birthweight infants: prospective ultrasound study. Lancet 1987;ii:593-6. 